\title{
Влияние температуры осаждения на структуру и оптические свойства пленок селенида цинка, полученных ВЧ магнетронным распылением
}

\author{
(С) В.Ф. Кобзиев, Р.М. Закирова, Н.В. Костенков, П.Н. Крылов , И.В. Федотова
}

Удмуртский государственный университет, 426034 Ижевск, Россия

ฯE-mail: ftt@udsu.ru

(Получена 22 ноября 2016 г. Принята к печати 28 ноября 2016 г.)

Исследовано влияние температуры конденсации на скорость роста, структуру и оптические свойства полученных ВЧ магнетронным распылением пленок селенида цинка. С увеличением температуры осаждения толщина пленок уменьшается. Поликристаллические пленки селенида цинка состоят из смеси кубической и гексагональной фаз с преобладанием кубической фазы. Показана корреляция величины показателя преломления и размеров кристаллитов.

DOI: $10.21883 /$ FTP.2017.06.44567.8455

\section{1. Введение}

$\mathrm{ZnSe}$ используется в микро-, опто- и акустоэлектронике в качестве базовых слоев детекторов различных типов излучения [1]. Создание светодиодов для видимой и особенно ультрафиолетовой областей спектра является актуальной задачей полупроводниковой оптоэлектроники. Одним из наиболее перспективных материалов для использования в устройствах этого типа является такой широкозонный полупроводниковый материал, как селенид цинка $(\mathrm{ZnSe})$. Селенид цинка в пленочном исполнении принадлежит к числу наиболее перспективных широкозонных материалов $\mathrm{A}^{\mathrm{II}} \mathrm{B}^{\mathrm{VI}}$ и находит широкое применение в устройствах коротковолновой полупроводниковой электроники и системах отображения информации [2,3]. Внимание к получению и исследованию свойств тонких пленок $\mathrm{ZnSe}$ обусловлено перспективами его применения в качестве материала для эффективного нелинейного преобразования оптических сигналов в устройствах обработки информации [4]. Проявление нелинейных свойств поликристаллических пленок связывают с их структурными особенностями [4], в этой связи представляет интерес исследование оптической нелинейности в зависимости от структуры и степени кристалличности осаждаемых пленок [5]. От нестехиометрии пленок соединений $\mathrm{A}^{\mathrm{II}} \mathrm{B}^{\mathrm{VI}}$ зависят электрофизические и оптические свойства [6].

В последнее время все шире находят применение поликристаллические материалы, получаемые различными методами: по керамической технологии (КТ), из жидкой фазы путем парофазного осаждения (ПО) и осаждением из газовой фазы (CVD). Материалы отличаются размерами зерен, совершенством и физическими свойствами. В поликристаллических материалах помимо вышеуказанных дефектов добавляются границы зерен, на которых происходит рассеяние света [7]. Методов получения поликристаллических пленок достаточно много.
Наибольшее распространение для получения пленок соединений $\mathrm{A}^{\mathrm{II}} \mathrm{B}^{\mathrm{VI}}$ получили вакуумные методы напыления, включая молекулярно-лучевую эпитаксию [8-19].

Цель данной работы заключается в получении пленок $\mathrm{ZnSe}$ методом ВЧ магнетронного напыления и исследовании их структуры и оптических свойств в зависимости от температуры осаждения.

\section{2. Методика эксперимента}

Тонкие пленки селенида цинка осаждали на предварительно очищенные стеклянные подложки и сколы монокристаллов $\mathrm{NaCl}$ методом ВЧ магнетронного распыления на модернизированной установке Катод-1М [20].

Предельное давление в камере составляло $4 \cdot 10^{-3}$ Па. Напыление проводили в среде аргона при рабочем давлении $2.5 \cdot 10^{-1}$ Па. Распыление мишени $\mathrm{ZnSe}$ производили при ВЧ мощности разряда 300 Вт, отраженная мощность была 14 Вт. Температуру подложек при напылении пленок $\mathrm{ZnSe}$ поддерживали 100, 150, 200, 250, $300,350,400$ и $500^{\circ} \mathrm{C}$. Измерение толщины пленки проводили на интерференционном микроскопе МИИ-4. Кроме того, для определения толщины, а также показателя пленок использовали конвертный метод [21]. Для этого с помощью СФ-56 в интервале длин волн 300-1100 нм снимали спектры пропускания и отражения.

Рентгенодифракционные исследования были выполнены на автоматизированном [22] дифрактометре ДРОН-3.0 в $\mathrm{Fe} K_{\alpha}$-излучении в диапазоне брэгговских углов от 30 до $80^{\circ}$. Размеры областей когерентного рассеяния (ОКР) оценивали по формуле СеляковаШеррера [23]. Для получения прецизионных значений параметра кристаллической решетки $a$ материала применяли экстраполяционный метод Нельсона-Райли [24]. По стандартной методике определяли макронапряжения $\left(\sigma_{1}+\sigma_{2}\right)[24]$.

Морфологию полученных пленок смотрели с помощью просвечивающей электронной микроскопии на 
электронном микроскопе ЭМ-125. Размеры зерен рассчитывали по методу секущих.

Спектры комбинационного рассеяния света (КРС) получены на измерительном комплексе Centaur U HR. Спектры микро-КРС регистрировали при комнатной температуре в геометрии обратного рассеяния. Возбуждение осуществлялось лазерами с длинами волн 473 и 532 нм (мощность лазера 45 мВт, время набора импульсов 100 c). Измерения проводили при комнатной температуре. Излучение фокусировалось объективом $(100 \times)$ с числовой апертурой $N_{\mathrm{A}}=0.90$, что обеспечивало размер фокусного пятна $\sim 1$ мкм при длине волны 473 нм.

\section{3. Результаты и обсуждение}

Проведенные исследования показали, что в процессе ВЧ магнетронного осаждения с увеличением температуры подложек толщина пленок селенида цинка уменьшается от $540\left(100^{\circ} \mathrm{C}\right)$ до $180 \mathrm{HM}\left(500^{\circ} \mathrm{C}\right)$ (рис. 1$)$.

Полученные результаты согласуются с результатами работ $[1,5,25]$. Согласно данным работы [1], уменьшение толщины пленок $\mathrm{ZnSe}$ с ростом температуры подложек связано с вторичным реиспарением материала. Авторы работы [25] считают, что диссоциация селенида цинка и десорбция компонент приводят к уменьшению частоты образования критических зародышей и, следовательно, к снижению скорости роста. В работе [5] скорость осаждения пленок $\mathrm{ZnSe}$ на подложки из плавленого кварца уменьшалась с ростом температуры подложки до $460 \mathrm{~K}$ $\left(187^{\circ} \mathrm{C}\right)$, а дальше увеличивалась. Уменьшение скорости осаждения пленок в интервале температур подложки до $460 \mathrm{~K}$ объясняется возрастанием десорбционного потока с поверхности подложки, а рост скорости осаждения при температурах подложки выше $460 \mathrm{~K}$ связывается с увеличением коэффициентов поверхностной диффузии осаждаемых компонентов, что приводит к увеличению скорости осаждения пленки.

Рентгенофазовый анализ показал, что при температуре осаждения $100^{\circ} \mathrm{C}$ формируются пленки селенида цинка с гексагональной структурой вюрцита (JCPDS № 15-105). При температуре осаждения $150-500^{\circ} \mathrm{C}$ основной фазой полученных пленок является кубическая структура сфалерита (JCPDS № 37-1463), с преиму-

Параметры решетки и микронапряжения пленок $\mathrm{ZnSe}$, осажденных при разных температурах

\begin{tabular}{c|c|c}
\hline$T,{ }^{\circ} \mathrm{C}$ & $a, \AA$ & $\sigma_{1}+\sigma_{2}, \Gamma \Pi \mathrm{a}$ \\
\hline 150 & 5.678 & -0.39 \\
200 & 5.679 & -0.43 \\
250 & 5.680 & -0.47 \\
300 & 5.682 & -0.56 \\
350 & 5.685 & -0.68 \\
400 & 5.688 & -0.81 \\
500 & 5.688 & -0.81
\end{tabular}

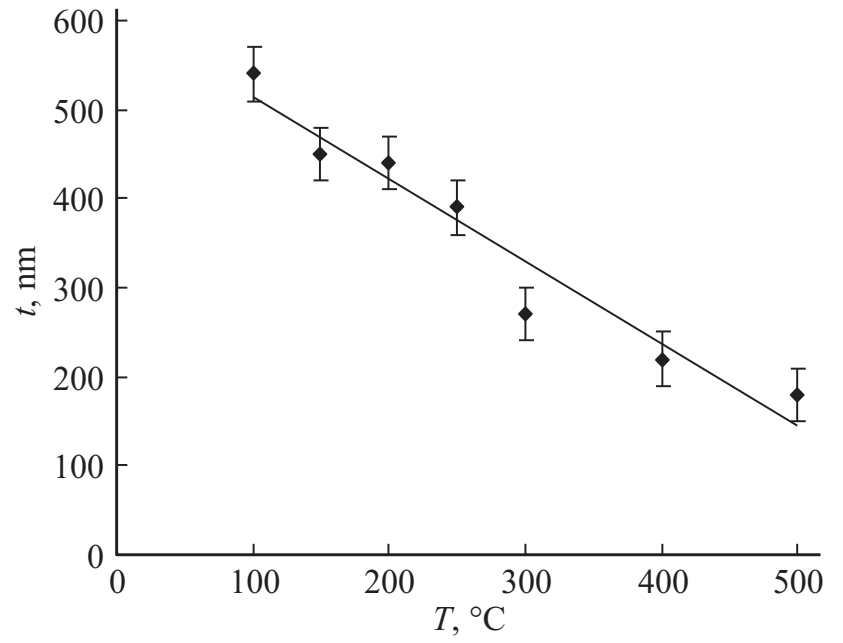

Рис. 1. Зависимость толщины пленок $\mathrm{ZnSe}$ от температуры подложки.

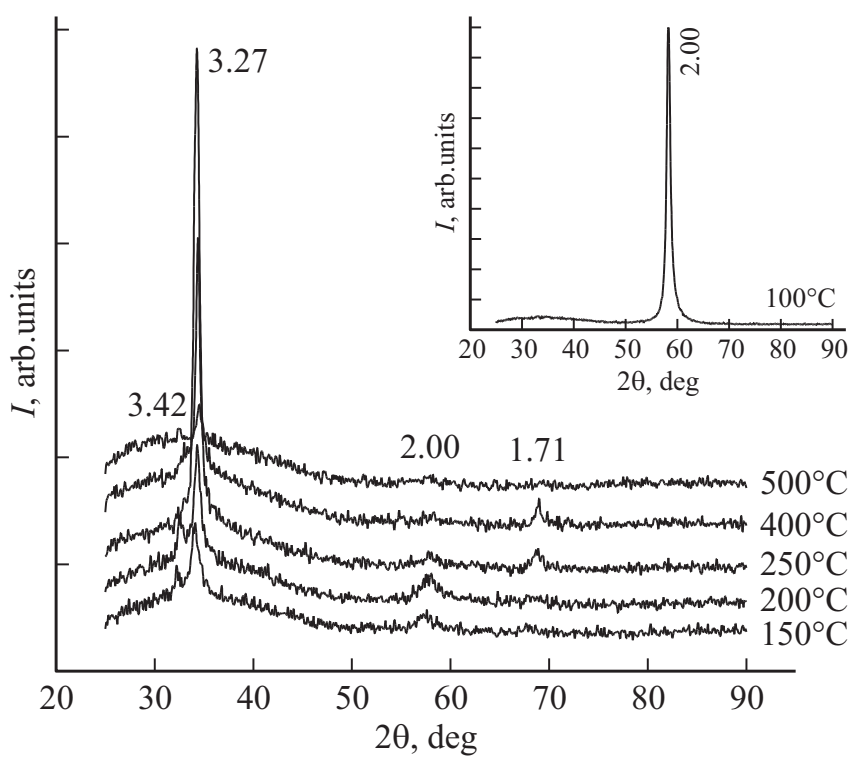

Рис. 2. Дифрактограммы пленок $\mathrm{ZnSe}$, полученных ВЧ магнетронным распылением при разных температурах осаждения. На вставке - дифрактограмма пленки $\mathrm{ZnSe}$, полученной при температуре подложки $100^{\circ} \mathrm{C}$.

щественной ориентацией кристаллитов вдоль направления [111], перпендикулярного к поверхности пленки. Также при этих температурах осаждения на дифрактограммах наблюдается слабое дифракционное отражение с межплоскостным расстоянием $3.44 \AA$, которое можно приписать селениду цинка с гексагональной структурой (рис. 2).

Интенсивность дифракционных отражений уменьшается с ростом температуры конденсации от 150 до $500^{\circ} \mathrm{C}$, что связано с уменьшением толщины пленки.

Оценка размеров областей когерентного рассеяния (ОКР), выполненная по линии (111), показала увели- 


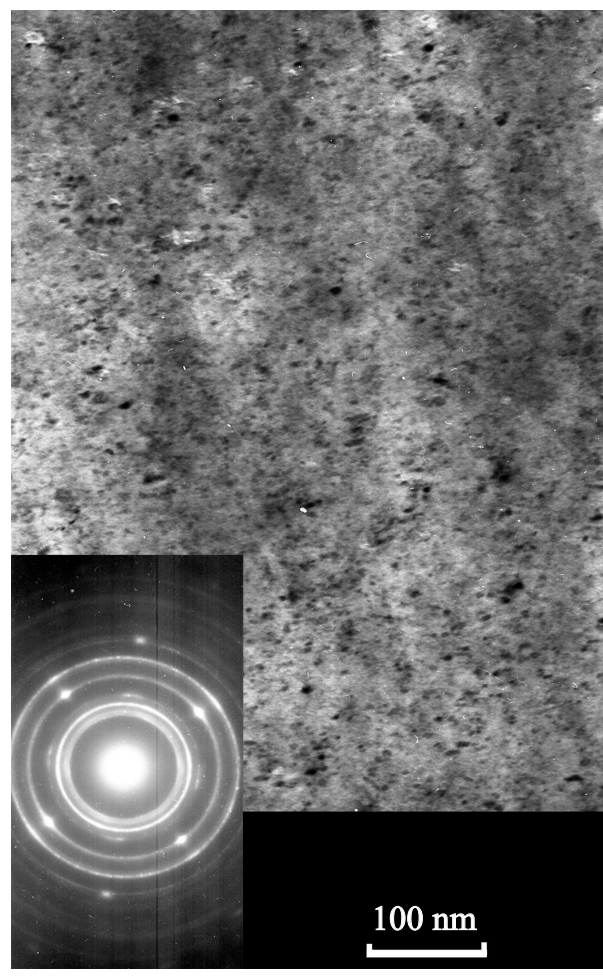

Pис. 3. Микроизображение и электронограмма тонкой пленки $\mathrm{ZnSe}$, полученной при температуре подложки $150^{\circ} \mathrm{C}$.

чение размеров ОКР селенида цинка от 8 до 17 нм с ростом температуры конденсации от 150 до $500^{\circ} \mathrm{C}$.

С ростом температуры осаждения увеличивается параметр решетки $a$ кубического селенида цинка (см. таблицу). Отличие параметра решетки от табличного значения $5.6688 \AA$ (JCPDS № 37-1463) свидетельствует о наличии напряженного состояния в системе пленка-подложка. Отрицательные значения напряжений $\left(\sigma_{1}+\sigma_{2}\right)$ исследуемых пленок $\mathrm{ZnSe}$ говорят об их сжимающем характере. Рост температуры осаждения приводит к увеличению уровня макронапряжений и размеров ОКР.

Сведения, полученные из анализа микроизображений и электронограмм, дополняют рентгенографические данные. На рис. 3 представлены микроизображение и электронограмма для образца, полученного при температуре осаждения $150^{\circ} \mathrm{C}$.

При температуре подложки $100^{\circ} \mathrm{C}$ пленка имеет мелкодисперсную структуру с включениями, на электронограмме видны широкие кольца с точечными рефлексами. По мере увеличения температуры осаждения наблюдается увеличение размеров кристаллитов. Так, при температурах 150 и $200^{\circ} \mathrm{C}$ на узких кольцах, принадлежащих селениду цинка, наблюдаются отдельные рефлексы, что характерно для поликристаллических пленок, имеющих ориентированные зерна.

При температурах конденсации 250 и $300^{\circ} \mathrm{C}$ на электронограммах видны сильные рефлексы, характерные для монокристаллов [26], и слабые дифракционные кольца, состоящие из точек.

Изменение среднего диаметра зерен тонких пленок $\mathrm{ZnSe}$ с увеличением температуры конденсации согласуется с изменением размеров ОКР.

Спектры пропускания и отражения носят осциллирующий характер. Средний коэффициент пропускания в диапазоне длин волн от 500 до 1100 нм составляет 80-95\%. Край поглощения пленок $\mathrm{ZnSe}$ при увеличении температуры осаждения смещается в коротковолновую область. В работе [5] предположили, что размытый край собственного поглощения, смещенный в длинноволновую область спектра, связан с несовершенством пленок и высокой концентрацией дефектов, обусловленных нарушением стехиометрии состава осаждаемого материала при повышении скорости роста.

Показатель преломления зависит от температуры напыления достаточно сложным образом: вначале с ростом температуры конденсации он увеличивается от 2.76 до 2.93 , начиная с $200^{\circ} \mathrm{C}$ уменьшается, при $300^{\circ} \mathrm{C}$ имеет минимальное значение (2.64), при дальнейшем повышении температуры он вновь возрастает до 2.85. Это, вероятно, связано со структурными особенностями растущих пленок. В работе [5] наблюдали корреляцию величины комплексного нелинейного показателя преломления и размеров кристаллитов в осаждаемой пленке селенида цинка. В данной работе показатель преломления пленки $n$ и коэффициент поглощения $k$ на длине волны 633 нм определяли волноводным методом. Показано, что при скоростях осаждения менее 5.0 нм/мин показатель преломления пленок близок к показателю монокристаллического $\mathrm{ZnSe}$ (2.52-2.58). Пленки, полученные при более высоких скоростях осаждения, имели низкий показатель преломления.

Согласно данным работы [27], относительная плотность (коэффициент упаковки, коэффициент заполнения) связана с показателем преломления массивного образца и пленки соотношением

$$
q=\frac{\rho_{f}}{\rho_{m}}=\frac{n_{f}^{2}-1}{n_{f}^{2}+2} \frac{n_{m}^{2}+2}{n_{m}^{2}-1},
$$

где $n_{f}$ и $n_{m}-$ показатели преломления пленки и массивного образца соответственно. Используя данную формулу и определенные значения показателей преломления, найдены изменения относительной плотности пленок с изменением температуры конденсации. Наибольшую относительную плотность имеют пленки, полученные при 200 и $500^{\circ} \mathrm{C}$, наименьшую - при $300^{\circ} \mathrm{C}$. Можно предположить, что при температуре осаждения $200^{\circ} \mathrm{C}$ пленки являются поликристаллическими с ориентированными зернами, при более высоких температурах появляется мозаика, структурное совершенство которой увеличивается по мере роста температуры конденсации.

По методике работы [1] построены спектральные зависимости коэффициента поглощения пленок $\mathrm{ZnSe}$ в координатах $(\alpha h v)^{2}-h v$, используемые в дальнейшем 

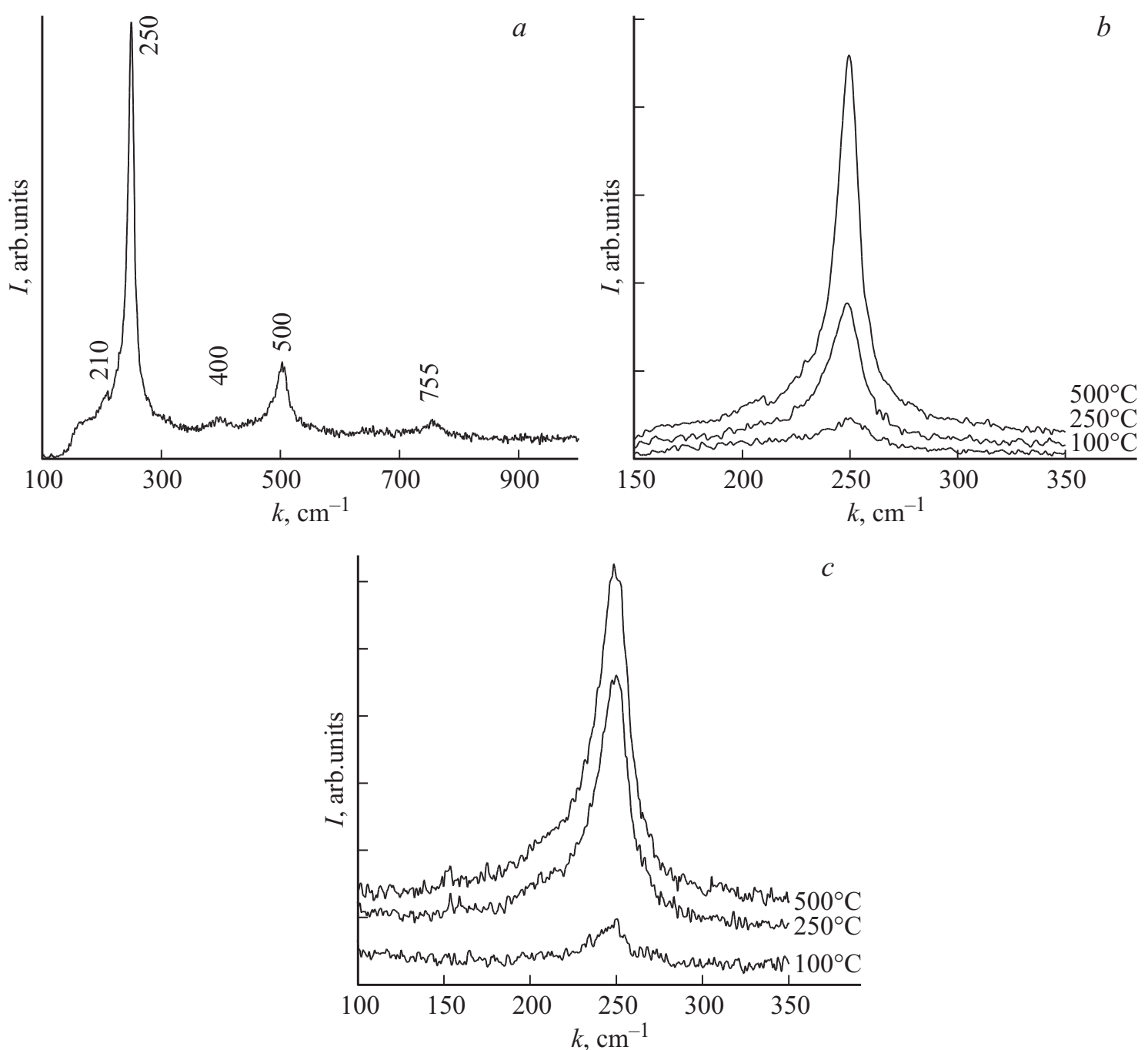

Рис. 4. Спектры КРС пленок ZnSe: $a$ - температура подложки $500^{\circ} \mathrm{C}$, длина волны лазера 473 нм; $b$ - полоса на частоте $250 \mathrm{~cm}^{-1}$, длина волны лазера $473 \mathrm{Hм} ; c$ - полоса на частоте $250 \mathrm{~cm}^{-1}$, длина волны лазера $532 \mathrm{Hм}$.

для определения ширины запрещенной зоны материала. C ростом температуры конденсации ширина запрещенной зоны увеличивается от 2.38 до 2.73 эВ. В работе [1] также наблюдали увеличение ширины запрещенной зоны с увеличением температуры подложки.

Вероятно, изменение ширины запрещенной зоны и параметра решетки при изменении температуры конденсации пленок связано с отклонением от стехиометрии и наличием второй фазы $[6,28,29]$.

На спектрах КРС пленок $\mathrm{ZnSe}$, полученных ВЧ магнетронным распылением, наблюдаются полосы на частотах 210, 250, 400, 500, $755 \mathrm{~cm}^{-1}$ (рис. 4, a).

На частотах 250, 500 и $755 \mathrm{~cm}^{-1}$ наблюдаются полосы, соответствующие продольным оптическим фононам (1LO, 2LO, 3LO) ZnSe [30].

Полоса на частоте $210 \mathrm{~cm}^{-1}$ может соответствовать ТО моде, которая становится активной из-за нарушения правил отбора, связанного с искажением кристаллической структуры на границе раздела пленка-подлож- ка [31] или с тем, что поликристаллические зерна в пленках ориентированы случайным образом [32].

Положение пиков КРС для пленок, полученных при разных температурах осаждения, не меняется, но изменяется их интенсивность. Изменение интенсивности зависит от длины волны возбуждающего излучения. Интенсивность пиков КРС, полученных при возбуждающем излучении 473 нм, увеличивается с ростом температуры подложки (рис. 4,b). Интенсивность пиков КРС, полученных при возбуждающем излучении 532 нм, напротив, уменьшается с ростом температуры подложки (рис. 4, c). Такое поведение можно связать с изменением ширины запрещенной зоны [32].

\section{4. Заключение}

Пленки $\mathrm{ZnSe}$, полученные ВЧ магнетронным распылением на модернизированной установке Катод-1М, являются поликристаллическими с достаточно высоким 
коэффициентом пропускания в видимой области спектра. При одинаковых условиях осаждения (ВЧ мощность, давление и время напыления) с увеличением температуры осаждения толщина пленок уменьшается от 0.54 до 0.18 мкм, изменяются размеры ОКР, коэффициенты преломления, относительная плотность и ширина запрешенной зоны.

Максимальной шириной запрещенной зоны обладают пленки, полученные при температуре конденсации $500^{\circ} \mathrm{C}$. Наибольшую относительную плотность имеют пленки, полученные при температурах конденсации 200 и $500^{\circ} \mathrm{C}$, наименьшую - при $300^{\circ} \mathrm{C}$. Предположено, что при температуре $200^{\circ} \mathrm{C}$ пленки являются поликристаллическими с ориентированными зернами, при более высоких температурах появляется мозаика, структурное совершенство которой увеличивается по мере роста температуры осаждения.

Работа выполнена в рамках госзадания (проект 16.7592.2017/БЧ).

\section{Список литературы}

[1] Е.М. Софронова, Д.С. Софронов, В.В. Стариков, Д.И. Курбатов, А.С. Опанасюк, П.В. Матейченко. Журн. наноэлектронной физики, 4 (4), 04016 (5cc) (2012).

[2] M. Aveu, J.S. Prener. Physics and Chemistry of II-VI Compounds (Amsterdam, North-Holland Publ. Co., 1967) p. 278.

[3] Физика соединений $A^{I I} B^{V I}$, под ред. А.Н. Георгобиани, М.К. Шейнкмана (М., Наука, 1986) с. 368.

[4] С.П. Апанасевич, О.В. Гончарова, Ф.В. Карпушко, Г.В. Синицин. ЖПС, 47, 200 (1987).

[5] А.В. Хомченко. ЖТФ, 67 (9), 60 (1997).

[6] Р.Р. Сайфутяров, А.В. Хомяков, Е.Н. Можевитина, И.Х. Аветисов. Успехи в химии и хим. технологии, XXVIII (6), 28 (2014).

[7] А.Н. Брызгалов, В.В. Мусатов, В.В. Бузько. ФТП, 38 (3), 322 (2004).

[8] Е.Г. Гончаров, Г.В. Семенов, Я.А. Угай. Химия полупроводников (Воронеж, ВГУ, 1995) с. 270.

[9] В.П. Зломанов, А.В. Новоселова. $P-T-X$-диаграммы состояния систем металл-халькоген (М., Наука, 1987) c. 207.

[10] И.В. Седова. Автореф. канд. дис. (СПб., РАН ФТИ им. А.Ф. Иоффе, 2006).

[11] Ю.К. Ежовский, О.В. Денисова. Физико-химические основы технологии полупроводниковых материалов: Учеб. пособие (СПб., СЗТУ, 2005) с. 80.

[12] А.А. Дунаев, Е.А. Гарибин, П.Е. Гусев, А.А. Демиденко, И.Л. Егорова, М.А. Крутов, И.А. Миронов, А.Н. Чиванов. Межсдунар. конф. „Прикладная оптика“ (СанктПетербург, 2012) ч. 2, с. 212.

[13] Н.Н. Мельник, В.С. Виноградов, И.В. Кучеренко, Г. Карчевски, О.С. Пляшечник. ФТТ, 51 (4), 787 (2009).

[14] Физика и химия соединений $A^{I I} B^{V I}$, под ред. С.А. Медведева (М., Мир, 1970) с. 624.

[15] В.В. Куколь, Е.Е. Лакин, В.Д. Путятин. Монокристаллы и техника (Харьков, ВНИИ Монокристалл, 1975) вып. 12, c. 14 .
[16] S.K. Lok, G. Wang, Y. Cai, N. Wang, Y.C. Zhong, K.S. Wong, I.K. Sou. J. Cryst. Growth, 311 (9), 2630 (2009).

[17] C.-W. Huang, H.-M. Weng, Y.-L. Jiang, H.-Y. Ueng. Thin Sol. Films, 517, 3667 (2009).

[18] Zhengbang Pi, Xiaolu Su, Chao Yang, Xike Tian, Fang Pei, Suxin Zhang, Jianhua Zheng. Mater. Res. Bulletin, 43, 1966 (2008).

[19] Chongfeng Guo, C.H. Choy, Dexiu Huang, Yueping Fang. J. Phys. Chem. Sol., 67 (4), 818 (2006).

[20] С.С. Алалыкин, Р.М. Закирова, В.Ф. Кобзиев, П.Н. Крылов, И.В. Федотова. Хим. физика и мезоскопия, 17 (3), 360 (2015).

[21] В.В. Брус, М.Н. Солован, Э.В. Майструк, И.П. Козярский, П.Д. Марьянчук, К.С. Ульяницкий, J. Rappich. ФТТ, 56 (10), 1886 (2014).

[22] С.С. Алалыкин, П.Н. Крылов. ПТЭ, 2, 149 (2005).

[23] Я.С. Уманский, Ю.А. Скаков, А.Н. Иванов, Л.Н. Расторгуев. Кристаллография, рентгенография и электронная микроскопия (М., Металлургия, 1982) с. 632.

[24] С.С. Горелик, Л.Н. Расторгуев, Ю.А. Скаков. Ренгенографический и электронографбческий анализ (М., Металлургия, 2002).

[25] И.Г. Неизвестный, С.П. Супрун, В.Н. Шумский. Автометрия, 4, 34 (1994).

[26] В.К. Вайнштейн. Структурная электронограбия (М., Изд-во АН СССР, 1956) с. 341.

[27] Е.Н. Котликов, Ю.А. Кузнецов, Н.П. Лавровская, А.Н. Тропин. Науч. приборостроение, 18 (3), 32 (2008).

[28] Термодинамика оксидов, под ред. И.С. Куликов: Справ. изд. (М., Металлургия, 1986) с. 344.

[29] Чан Конг Кхань. Автореф. канд. дис. (М., Российский хим.технол. ун-т им. Д.И. Менделеева, 2016).

[30] S. Venkatachalam, Y.L. Jeyachandran, P. Sureshkumar, A. Dhayalraj, D. Mangalaraj, Sa.K. Narayandass, S. Velumani. Mater. Characterization, 58, 794 (2007).

[31] Л.К. Водопьянов, Н.Н. Мельник, Ю.Г. Садофьев. ФТП, 33 (3), 282 (1999).

[32] D. Nesheva, M.J. Šćepanović, S. Aškrabić, Z. Levi, I. Bineva, Z.V. Popović. Acta Phys. Polon. A, 116 (1), 75 (2008).

Редактор А.Н. Смирнов

\section{Effect of deposition temperature on the structure and optical properties of zinc selenide films prepared RF magnetron sputtering}

\author{
V.F. Kobziev, R.M. Zakirova, N.V. Kostenkov, \\ P.N. Krylov, I.V. Fedotova
}

Udmurt State University, 426034 Izhevsk, Russia

Abstract The effect of deposition temperature on the rate of growth, structure and optical properties of zinc selenide films prepared the RF magnetron sputtering are investigated. The film thickness decreases with increasing deposition temperature. Polycrystalline zinc selenide films consist of a mixture of cubic and hexagonal phases with dominate cubic phase. A correlation of value of the refractive index and crystallite size are shown. 